\title{
Modeling and Molecular Spectroscopic Analyses of Cellulose
}

\author{
Abdel Aziz Mahmoud ${ }^{1}$, Osama Osman ${ }^{1}$, Walid El-hotaby ${ }^{1}$, Ahmed Fakhry ${ }^{1}$, \\ Zainab Abdel Aziz ${ }^{1}$, Medhat Ibrahim ${ }^{1, *}$ and Hanan Elhaes ${ }^{2}$ \\ ${ }^{1}$ Spectroscopy Department, National Research Centre, 12311 Dokki, Cairo, Egypt \\ ${ }^{2}$ Physics Department, Faculty of Women for Arts, Science and Education, Ain Shams University, 11757 \\ Cairo, Egypt
}

\begin{abstract}
Cellulose is the most abundant biopolymer which is a topic of extensive research work. In this study Fourier Transform Infrared Spectroscopy (FTIR) was utilized to assign the molecular structure of cellulose. B3LYP at 3-21 ${ }^{* *}, 6-$ $31 \mathrm{~g}^{\star *}$ and LANL1DZ then MP2 at $6-31 \mathrm{~g}^{*}$ levels of theories were conducted to compare the calculated vibrational spectra with the FTIR spectrum. Model molecules of cellulose starting with monomer up to cellulose 18 units were studied with PM3 semiemperical method in order to follow up the effect of polymerization upon some selected physical parameters. Results indicate that final heat of formation and band gap energy have decreased with increasing cellulose units while total dipole moment has increased with increasing cellulose units. It is concluded that the reactivity of cellulose has increased with increasing the units also the unique hydrogen bonding dedicates cellulose to several applications.
\end{abstract}

Keywords: Cellulose, FTIR, PM3, DFT and Physical properties.

\section{INTRODUCTION}

Cellulose is considered as a simple polymer, being the most abundant carbohydrate produced by plants. It is a topic of research work as biopolymers are characterized with several biological and chemical properties [1-8]. Cellulose was subjected to spectroscopic analyses using Fourier Transform Infrared spectroscopy FTIR with the help of molecular modelling [9], the study indicated that cellulose has unique hydrogen bonding which allows it to be functionalized using reactive functional groups which in turn increases its applications. Water hyacinth was treated as cellulose like materials in order to utilize it as an effective tool for removing heavy metals from the aquatic environment [10]. Both FTIR and molecular modeling was used to understand the mechanism of metal uptake by the cellulose of the plant. The study was further modified to treat the plant as cellulose like material together with metal oxides and lignin [11]. Cellulose was compared with chitosan and both were subjected to molecular modeling study to indicate the effect of polmerization on their physcial properties, the study included up to 8 units [12]. Molecular modeling at different level of theories proves their effective applications for elucidating structural, physcial, chemical as well as biological properties for many systems and molecules [13-16]. It is stated that molecular modeling could be helpful when the experimental tools are limited or even unavailable [1718]. It could be also an effective tool to start certain

*Address correspondence to this author at the Spectroscopy Department, National Research Centre, 12311 Dokki, Cairo, Egypt; Tel: +201222727636; Fax: +20233370931; E-mail: medahmed6@yahoo.com experimental work and/or understanding the mechanism of interaction for a given experimental work [19-21].

Based on the above considerations FTIR will be utilized to study cellulose standard then molecular modeling will be used to study cellulose monomer. PM3 level of theory will be utilized to follow up the effect of polmerization on the physical properties of cellulose up to 18 units. Some important parameters like, final heat of formation, band gap energy and total dipole moment will be evaluated.

\section{MATERIALS AND METHODS}

Cellulose standard was purchased from SigmaAldrich Chemicals (molecular weight for each is 180.16). Cellulose then was mixed with $\mathrm{KBr}(1 \% \mathrm{~W} / \mathrm{W})$ and pressed in pellets to be ready for FTIR measurement. The FTIR spectrum was collected using Fourier Transform Infrared Spectrometer JASCO, FTIR- 300 $E$. , in the range of 400 to $4000 \mathrm{~cm}^{-1}$ at Spectroscopy Department, National Research Centre, Egypt.

\section{COMPUTATIONAL DETAILS}

All calculations are carried out upon cellulose monomer with the Gaussian 03 program system [22]. The geometry of cellulose monomer (Figure 1) is optimized by performing the density functional theory (DFT) at the hybrid Becke 3-Lee-Yang-Parr (B3LYP) exchange correlation functional [23-25] with three basis sets namely $3-21 \mathrm{~g}^{* *}, 6-31 \mathrm{~g}^{* *}$ and LANL1DZ. Another calculation is conducted at MP2/6-31 $\mathrm{g}^{*}$ level of theory. 


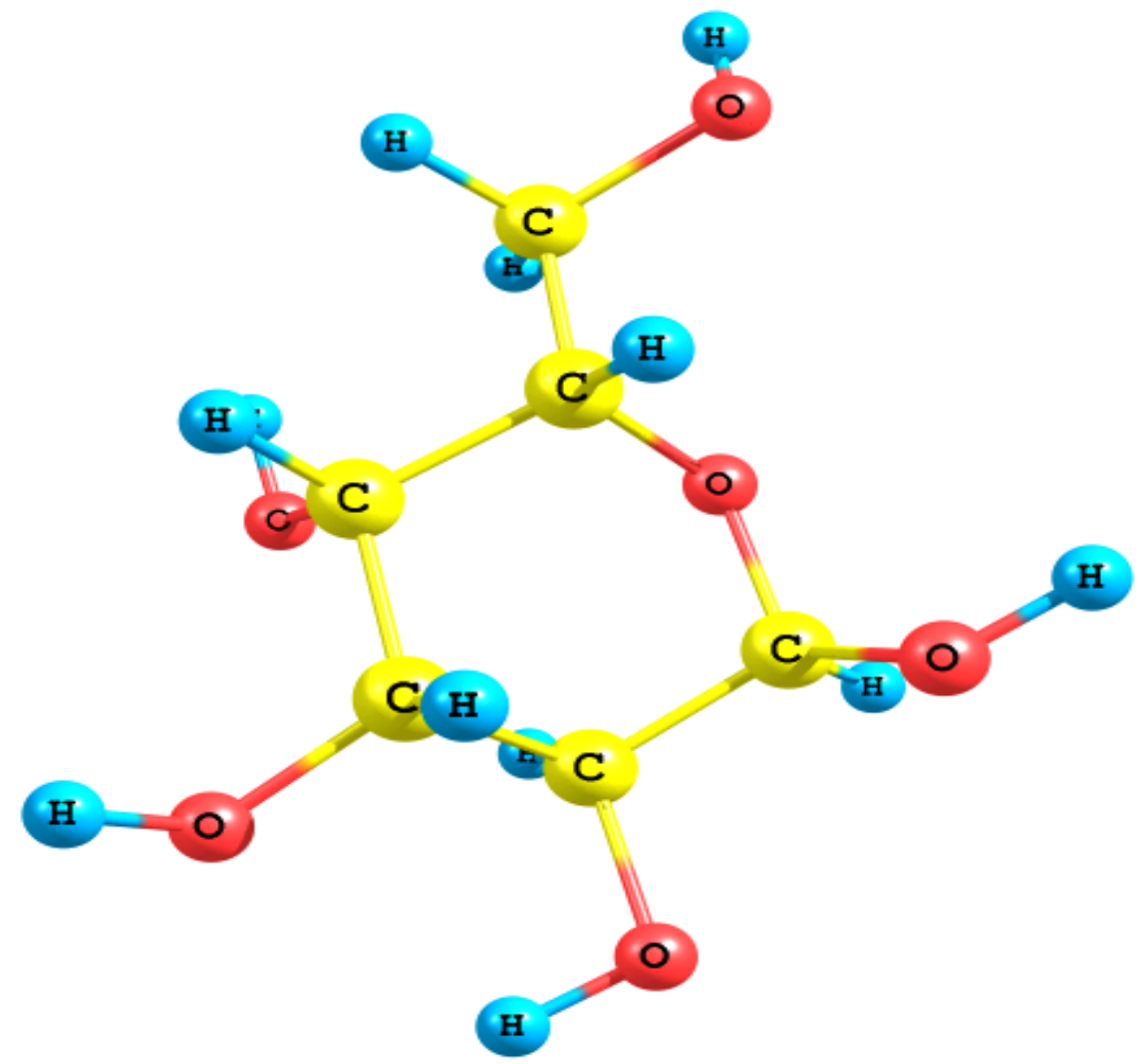

Figure 1: The cellulose monomer which is the proposed model molecule in the present study.

Model molecules of cellulose were built up to 18 units. The geometries of the model molecules were optimized using PM3 [26] semiemperical quantum mechanical calculations with a personal computer performed using quantum mechanical methods as implemented with the Scigress program system by Fujitsu [27]. The total dipole moment and HOMO-
LUMO energy were calculated at the same level of theory.

\section{RESULTS AND DISCUSSIONS}

Cellulose was subjected to optimization at four models namely B3LYP/3-21 $\mathrm{g}^{* *}$, B3LYP/6-31 $\mathrm{g}^{* *}$, B3LYP/LANL1DZ and MP2/6-31g*. The calculations

Table 1: Experimental FTIR Absorption Bands Frequencies and their Assignment for Cellulose as Compared with Scaled Calculated Frequencies at B3LYP/3-21g**, B3LYP/ 6-31g **, B3LYP/ LANL1DZ and MP2/6-31g* Models

\begin{tabular}{|c|c|c|c|c|c|}
\hline \multirow{2}{*}{ FTIR } & \multicolumn{3}{|c|}{ B3LYP } & \multirow{2}{*}{$\begin{array}{c}\text { MP2 } \\
\text { 6-31g* }\end{array}$} & \multirow{2}{*}{ Assignment } \\
\hline & $3-21 g^{* *}$ & $6-31 g^{* *}$ & LANL1DZ & & \\
\hline 3348 & 3534 & 3648 & 3576 & 3530 & $\mathrm{OH}$ \\
\hline 2900 & 2960 & 2895 & 2969 & 2910 & $\mathrm{CH}$ symmetric stretching \\
\hline 1640 & & & & & $\mathrm{C}-\mathrm{O}$ \\
\hline 1430 & 1468 & 1457 & 1466 & 1469 & $\mathrm{CH}_{2}$ vibration \\
\hline $1372 \sim 1336$ & & & & & Split $\mathrm{CH}_{3}$ umbrella mode. \\
\hline 1318 & 1297 & 1300 & 1315 & 1280 & $\mathrm{C}-\mathrm{CH}$ \\
\hline 1281 & 1267. & 1274 & 1287 & & $\mathrm{C}-\mathrm{CO}$ \\
\hline $1162 \sim 1032$ & 1102 & 1079 & 1086 & 1059 & $\mathrm{C}-\mathrm{O}-\mathrm{C}$ \\
\hline 897 & 939 & 965 & 888 & 886 & $\mathrm{C}-\mathrm{H}$ \\
\hline 615 & 600 & 618 & 624 & 541 & $\mathrm{CH}_{2}$ \\
\hline
\end{tabular}




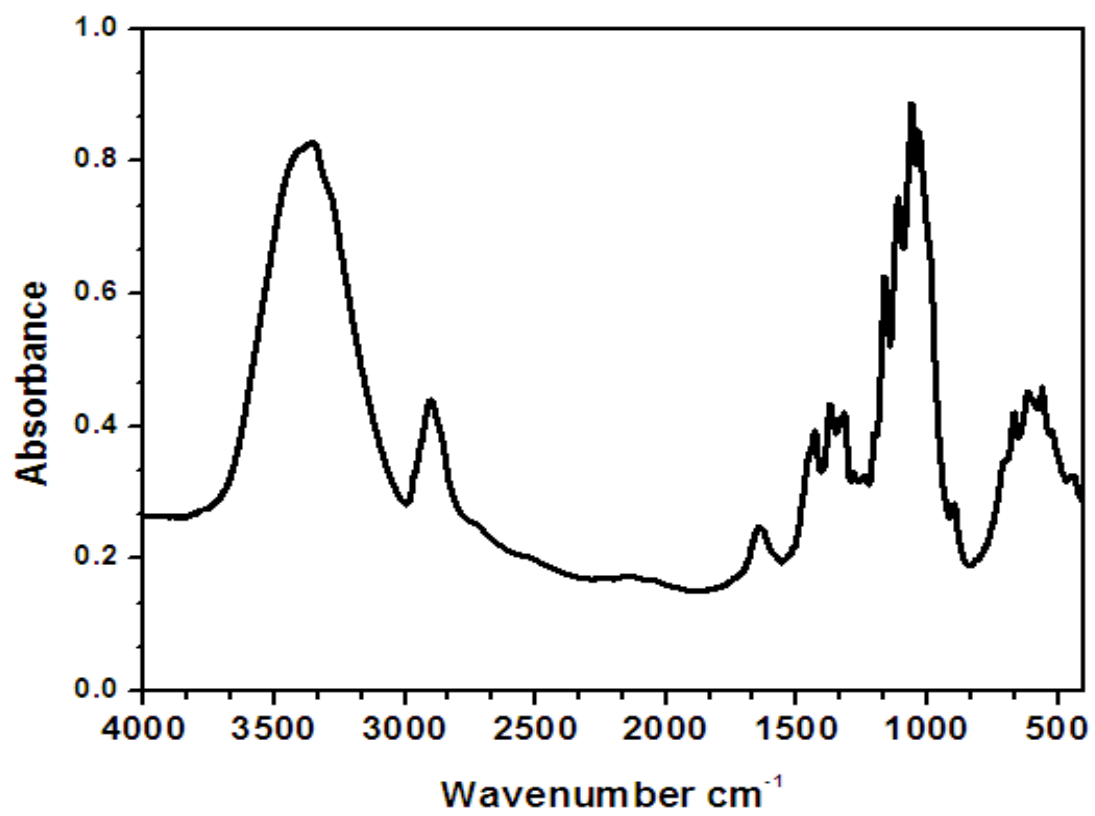

Figure 2: FTIR absorption spectra of the cellulose.

were carried out upon cellulose monomer as indicated in Figure 1. Scaled vibrational frequencies were calculated upon the optimized structure then compared with the FTIR experimental spectrum as indicated in Table 1.

\subsection{FTIR Study of Cellulose}

FTIR absorption bands for standard cellulose are given in Figure $\mathbf{2}$ while the assignment is given in Table 1. The assignment is first aided by the model program and is in good agreement with that obtained by Bouchard and Douek [28]. The $\mathrm{OH}$ stretching vibration is located at $3348 \mathrm{~cm}^{-1}$, the $\mathrm{CH}$ symmetric stretching vibration of $\mathrm{CH}_{2}$ is located around $2900 \mathrm{~cm}^{-1}$ and the stretching vibration of $\mathrm{C}-\mathrm{O}$ at $1640 \mathrm{~cm}^{-1}$. The $\mathrm{CH}_{2}$ vibration has another band at $1430 \mathrm{~cm}^{-1}$ and the split band of $\mathrm{CH}_{3}$ umbrella mode is located at $1372 \sim 1336$ $\mathrm{cm}^{-1}$ (bending vibrations). Then the $\mathrm{C}-\mathrm{CH}$ bending vibration appears at $1318 \mathrm{~cm}^{-1}$. The characteristic bands of cellulose are mainly observed around $1000 \sim 1200 \mathrm{~cm}^{-1}$. The band at $1160 \mathrm{~cm}^{-1}$ is attributed to the antisymmetric bridge stretching of C-O-C groups in cellulose and hemi-cellulose. The band at $1318 \mathrm{~cm}^{-1}$ could be ascribed to $\mathrm{CH}_{2}$-wagging vibrations in cellulose and hemi-cellulose. The band at $895 \mathrm{~cm}^{-1}$ is described as the $\beta$-linkages, especially in hemicelluloses which are in good agreement with the data obtained by Michell [29].

The errors within the computational methods are systematic and could be corrected with scale factor for comparison with experimental results.
For B3LYP we found the scale factors 0.9585 , 0.9613 and 0.9700 for the basis sets $3-21 \mathrm{~g}^{* *}, 6-31 \mathrm{~g}^{* *}$ and LANL1DZ respectively [30-31]. While for MP2/6$31^{*}$ the scale factor is 0.9427 [30]. Comparing both experimental and scale calculated spectra one can observe the absence of two bands namely $\mathrm{C}-\mathrm{O}$ and Split $\mathrm{CH}_{3}$ umbrella mode. This is due to the fact that, the calculation is carried out upon cellulose monomer, which leads to the absence of these two bands.

\subsection{Calculated Physical Parameters}

Both calculated and measured spectra for cellulose suggest that the structure has many hydrogen bonding which dedicate it for many applications based upon its ability for surface interaction as well as chemical and biological interactions. More details could be achieved as one calculates electronic properties of cellulose on going from one unit up to 18 units.

Table 2 shows some important physical parameters such as the final heat of formation, highest occupied molecular orbital (HOMO)- lowest unoccupied molecular orbital (LUMO) energy band gap and total dipole moment for cellulose one unit up to 18 units. The calculations were carried out with PM3 semiemperical quantum mechanical method at $300 \mathrm{k}$. These parameters are calculated in order to follow up the effect of polymerization in terms of these calculated parameters.

Table 2 indicates that the final heat of formation has decreased on going from one unit of cellulose up to18 
Table 2: Calculated Final Heat of Formation (HF) as Kcal/mol, HOMO-LUMO Energy Band Gap ( $\Delta E$ ) as eV and Total Dipole Moment (DM) as Debeye for Cellulose One Unit Up to 18 Units Respectively at PM3 Semiemperical Quantum Mechanical Method, at the Temperature $300 \mathrm{k}$

\begin{tabular}{|c|c|c|c|}
\hline Units & HF (Kcal/mol) & $\Delta \mathrm{E}(\mathrm{eV})$ & DM (Debeye) \\
\hline \hline $\mathrm{C}_{1}$ & -270 & 12.945 & 3.1 \\
\hline $\mathrm{C}_{4}$ & -877 & 12.127 & 10.4 \\
\hline $\mathrm{C}_{8}$ & -1688 & 12.002 & 12.0 \\
\hline $\mathrm{C}_{9}$ & -1892 & 11.992 & 12.5 \\
\hline $\mathrm{C}_{10}$ & -2106 & 11.766 & 13.1 \\
\hline $\mathrm{C}_{13}$ & -2735 & 11.559 & 23.9 \\
\hline $\mathrm{C}_{14}$ & -2982 & 11.431 & 24.6 \\
\hline $\mathrm{C}_{15}$ & -3158 & 11.741 & 25.8 \\
\hline $\mathrm{C}_{18}$ & -3704 & 11.677 & \\
\hline
\end{tabular}

cellulose units. The band gap energy is calculated as the difference between HOMO-LUMO. The calculated energy band gap shows the same behavior as the final heat of formation. The highest energy gap was found to be $12.945 \mathrm{eV}$, this value is corresponding to the cellulose monomer. The energy gap has then decreased with increasing the cellulose units up to 18 units $(11.677 \mathrm{eV})$. The opposite behavior is observed for the calculated total dipole moment whereas it has increased with increasing the number of cellulose units. The total dipole moment for cellulose monomer is 2.1 Debye while the total dipole moment corresponding to cellulose 18 units is found to be 25.8 Debye. It is stated earlier that the reactivity of a given structure is a function of its physical parameters such as dipole moment and energy band gap [13, 32]. As far as the dipole moment has increased and the band gap energy decreased the reactivity has increased. Applying these upon the calculated parameters for cellulose one can notice an increase in total dipole moment with decrease in both final heat of formation and band gap energy. This in turn indicates that increasing the number of cellulose units increases the reactivity of cellulose.

\section{CONCLUSION}

The FTIR spectrum of cellulose indicates that this biopolymer has many hydrogen bonding which allow it for further interaction with other biopolymers as well as reactive molecules. In order to investigate the reasons behind the functionality of cellulose, the PM3 method is consulted. Results indicate that increasing the cellulose units increases the total dipole moment while both heat of formation and energy band gap have decreased.
These results indicate that cellulose reactivity increased as the number of cellulose units increases. This could be due to increasing the hydrogen bonding which is confirmed by the FTIR results. We believe that molecular modeling through the calculated spectral and physical parameters is confirming the experimental FTIR analyses and both are considered as useful tools for investigating the reactivity of biopolymers as well as many other structures.

\section{REFERENCES}

[1] Heinze T, Liebert T. Unconventional methods in cellulose functionalization. Prog Polym Sci 2001; 26: 1689-762. http://dx.doi.org/10.1016/S0079-6700(01)00022-3

[2] Numata Y, Kono H, Kawano S, Erata T, Takai M. Crosspolarization/magic-angle spinning $13 \mathrm{C}$ nuclear magnetic resonance study of cellulose l-ethylenediamine complex. Biosci J Bioeng 2003; 96: 461-6.

http://dx.doi.org/10.1016/S1389-1723(03)70132-7

[3] OH SY, Yoo DI, Shin Y, et al. Crystalline structure analysis of cellulose treated with sodium hydroxide and carbon dioxide by means of X-ray diffraction and FTIR spectroscopy. Carbohyd Res 2005; 340: 2376-91. http://dx.doi.org/10.1016/j.carres.2005.08.007

[4] Beatriz AP, Ass AP, Ciacco GT, Frollini E. Cellulose acetates from linters and sisal: Correlation between synthesis conditions in $\mathrm{DMAc} / \mathrm{LiCl}$ and product. Bioresource Technol 2006; 97: 1696-702. http://dx.doi.org/10.1016/j.biortech.2005.10.009

[5] Song Y, Zhou J, Zhang L, Wu X. Homogenous modification of cellulose with acrylamide in $\mathrm{NaOH} /$ urea aqueous solutions. Carbohyd Polym 2008; 73: 18-25.

\section{http://dx.doi.org/10.1016/j.carbpol.2007.10.018}

[6] Grande CJ, Torres FG, Gomez CM, Bano MC. Nanocomposites of bacterial cellulose/hydroxyapatite for biomedical applications. Acta Biomaterialia 2009; 5: 1609-15. http://dx.doi.org/10.1016/j.actbio.2009.01.022

[7] Yun S, Kim J. Mechanical, electrical, piezoelectric and electro-active behavior of aligned multi-walled carbon nanotube/cellulose composites. Sensors Actuat A-Phys 2009; 154: 73-8. 
[8] Zimmermann T, Bordeanu N, Strub E. Properties of nanofibrillated cellulose from different raw materials and its reinforcement potential. Carbohyd Polym 2010; 79: 1086-93. http://dx.doi.org/10.1016/j.carbpol.2009.10.045

[9] Ibrahim M, Osman O. Spectroscopic Analyses of Cellulose: Fourier Transform Infrared and Molecular Modelling Study. J Comput Theor Nanosci 2009; 6: 1054-58. http://dx.doi.org/10.1166/jctn.2009.1143

[10] Ibrahim M, Kühn O, and Scheytt T. Molecular Spectroscopic Study of Water Hyacinth Dry Matter. TOCPJ 2009; 2: 1-6. http://dx.doi.org/10.2174/1874412500902010001

[11] Ammar NS, Elhaes H, Ibrahim HS, El-hotaby W, Ibrahim MA. A Novel Structure for Removal of Pollutants from Wastewater. Spectrochim Acta A 2014; 121C: 216-23. http://dx.doi.org/10.1016/j.saa.2013.10.063

[12] Ibrahim M, Osman O, Mahmoud A-A. Spectroscopic analyses of cellulose and chitosan: FTIR and modeling approach. J Comput Theor Nanosci 2011; 8: 117-23. http://dx.doi.org/10.1166/jctn.2011.1668

[13] Ibrahim M, El-Haes H. Computational spectroscopic study of copper, cadmium, lead and zinc interactions in the environment. Int J Environ Pollut 2005; 23: 417-23. http://dx.doi.org/10.1504/IJEP.2005.007604

[14] Elhaes H, Khafagy M, Ibrahim M. Spectroscopic Analyses of PVDX (X = F, Cl and Br). J Comput Theor Nanosci 2014; 11: 2115-19.

http://dx.doi.org/10.1166/jctn.2014.3614

[15] Elhaes $\mathrm{H}$, Attallah $\mathrm{M}$, Elbashar $\mathrm{Y}$, Al-Alousi A, El-Okr M, Ibrahim M. Modeling and Optical Properties of P2O5-ZnO$\mathrm{CaO}-\mathrm{Na} 2 \mathrm{O}$ Glasses Doped with Copper Oxide. J Comput Theor Nanosci 2014; 11: 2079-84. http://dx.doi.org/10.1166/jctn.2014.3608

[16] Mostafa HIA, El-bialy NS, Ezat AA, Saleh NA, Ibrahim MA. QSAR analysis and Molecular docking simulation of suggested Peptidomimetic NS3 Protease Inhibitors. Curr Comput-Aided Drug Des 2014; 10(1): 28-40.

http://dx.doi.org/10.2174/15734099113096660048

[17] Abdel-Gawad A-E A, Ibrahim M. Computational Studies of The Interaction of Chitosan Nanoparticles and aB-Crystallin. BioNanoScience 2013; 3: 302-11. http://dx.doi.org/10.1007/s12668-013-0096-3

[18] Elhaes $H$, Ibrahim M. Exploring Materials: Molecular Modeling Approach. Rev Theor Sci 2013; 1: 368-76. http://dx.doi.org/10.1166/rits.2013.1012

[19] Ibrahim M, El-Nahass MM, Kamel MA, El-Barbary AA, Wagner BD El-Mansy MA. On the Spectroscopic Analyses of Thioindigo Dye. Spectrochim Acta A 2013; 113: 332-6. http://dx.doi.org/10.1016/.j.saa.2013.05.014

[20] Al-Fifi Z, Eid M, Saleh NA, Ibrahim M. Molecular Modelling Analyses of the Substituted 3'-Azido-2', 3'Dideoxythymidine. J Comput Theor Nanosci 2014; 11: 409-12. http://dx.doi.org/10.1166/jctn.2014.3369
[21] El-Nahass MM, Kamel MA, El-Barbary AA, El-Mansy MAM, Ibrahim M. FT-IR spectroscopic analyses of 3-Methyl-5Pyrazolone (MP). Spectrochim Acta A 2013; 111: 37-41. http://dx.doi.org/10.1016/.saa.2013.03.072

[22] Frisch MJ, Trucks GW, Schlegel HB, Scuseria GE, Robb MA Cheeseman JR, Montgomery JA, Jr, Vreven T, Kudin KN, Burant JC, Millam JM, lyengar SS, Tomasi J, Barone V, Mennucci B, Cossi M, Scalmani G, Rega N, Petersson GA, Nakatsuji $H$, Hada $M$, Ehara $M$, Toyota K, Fukuda R, Hasegawa J, Ishida M, Nakajima T, Honda Y, Kitao O, Nakai $\mathrm{H}$, Klene M, Li X, Knox JE, Hratchian HP, Cross JB, Adamo C, Jaramillo J, Gomperts R, Stratmann RE, Yazyev O, Austin AJ, Cammi R, Pomelli C, Ochterski JW, Ayala PY, Morokuma K, Voth GA, Salvador P, Dannenberg JJ, Zakrzewski VG, Daniels AD, Farkas O, Rabuck AD, Raghavachari K,Ortiz JV, GAUSSIAN03, Revision B.05, Gaussian Inc., Wallingford CT, 2003.

[23] Becke AD. Density-functional thermochemistry. III. The role of exact exchange. J Chem Phys 1993; 98: 5648-52. http://dx.doi.org/10.1063/1.464913

[24] Keith TA, Bader RFW. Calcuaiion of magnetic response properties using atoms in molecules. Chem Phys Lett 1992; 194: 1-8. http://dx.doi.org/10.1016/0009-2614(92)85733-Q

[25] Lee C, Yang W, Parr RG. Development of the Colle-Salvetti correlation-energy formula into a functional of the electron density. Phys Rev B 1988; 37: 785 -9.

[26] Dewar MJS, Zoebisch EG, Healy EF, Stewart JP. AM1: a new general purpose quantum mechanical molecular model. J Am Chem Soc 1985; 107: 3902-9. http://dx.doi.org/10.1021/ja00299a024

[27] Stewart JJP, MO-G Version 1.1A, Fujitsu Limited, Tokyo, Japan 2008.

[28] Bouchard J, Douek M. Structural and Concentration Effects on the Diffuse Reflectance FTIR Spectra of Cellulose, Lignin and Pulp. J Wood Chem Technol 1993; 13: 481-99. http://dx.doi.org/10.1080/02773819308020530

[29] Michell AJ. Second Derivative FTIR Spectra of Woods edited by Schuerch C. Cellulose and Wood Chemistry and Technology, Wiley, New York, p. 995; 1989-08.

[30] Foresman JB, Frisch A, Exploring chemistry with electronic structure methods, Chap., 1, computational models and model chemistry, 2nd ed., Gaussian Inc. 1996.

[31] Xu X, Xie D, Xue Y, Yan G. Density functional theory study on fundamental vibrational spectra of disilyl iodide and its isotopomer. Spectrochim Acta A 2000; 56: 567-74. http://dx.doi.org/10.1016/S1386-1425(99)00155-9

[32] Ibrahim M, Mahmoud A-A. Computational notes on the reactivity of some functional groups. J Comput Theor Nanosci 2009; 6: 1523-6.

http://dx.doi.org/10.1166/jctn.2009.1205 